\title{
Source sink relationship, dry matter and starch partitioning in developing ginger rhizomes during different growth stages
}

\author{
K.S. Krishnamurthy* and K. Kandiannan ${ }^{1}$ \\ ICAR-Indian Institute of Spices Research, Kozhikode-673 012, Kerala, India \\ ${ }^{1}$ Vivekananda Technical Centre, Nadi, Fiji
}

(Manuscript Received: 05-06-2020, Revised:02-12-2020, Accepted:15-01-2021)

\begin{abstract}
Source sink relationship, dry matter and starch partitioning, rhizome bulking process in relation to dry matter and starch partitioning in developing rhizomes and growth and gas exchange parameters were studied in three popular varieties of ginger viz., IISR Varada, IISR Mahima and IISR Rejatha. Results revealed that maximum tiller production and leaf area accumulation occurred between 60 and 120 days after planting (DAP) in all three varieties. Photosynthetic rate and hormone contents (auxin and cytokinin) increased from 90-120 DAP, peaked at 120 DAP and then started declining. Biomass partitioning data revealed that the active biomass accumulation stage was between 60 and 150 DAP in ginger. The dry matter accumulation pattern in rhizomes also revealed that maximum dry matter accumulation in rhizomes also occurred between 60 and 150 DAP in all the three varieties. Maximum starch accumulation in the rhizomes also occurred during the same period. These results suggest that most of the rhizome bulking process occurred between 60 and 150 DAP in ginger. Total biomass accumulation, dry matter accumulation and starch accumulation in rhizomes followed similar trends.
\end{abstract}

Keywords: Bulking, ginger source, partitioning, photosynthetic rate, rhizome, sink, transpiration rate

\section{Introduction}

Source sink relationship and partitioning of dry matter and metabolites in ginger form the basis for understanding the rhizome development process. Initiation, bulking and termination of rhizome development in ginger are not studied. Proper understanding of these development stages may help in regulating the rhizome growth externally based on our needs. Plant hormones may have a critical role in rhizome initiation and bulking. Similarly, the role of photosynthesis in rhizome development is not clear. The seed rhizome size influences the final rhizome bulking and yield, and the study showed that the greater the seed rhizome size, the greater the fresh rhizome production (Suhaimi et al., 2016). There are a few studies in potato in this direction. Root mass was negatively correlated with early tuber bulking in potato. However, root mass generally shows positive correlations with shoot mass and final tuber yield (Iwama, 2008). The source-sink relationship was modified by a sink extension in potato; the foliar application of $\mathrm{K}_{2} \mathrm{SO}_{4}$ accelerated the tuber development. Potato plants expressing chimeric cytokinin synthesis gene had better shoot development and tuberization (Tao et al., 2010), indicating the influence of cytokinins on tuber development. In sweet potato, the growth rate decreased between 45 and 75 days after planting, which may be related to tuberization and secondary vine onset. Later, a significant increase in growth rate was noticed till 90 days after planting, which may be associated with the efficient accumulation of biomass in tubers ( $\mathrm{P}^{\prime}$ erez-Pazos et al., 2021). But information is lacking on source-sink transition, partitioning of dry matter and metabolites to various organs during different growth stages, rhizome bulking process and the relationship between photosynthesis and rhizome development etc. Hence, the present study was conducted with the following objectives.

*Corresponding Author: kskrishnamurthy@gmail.com 
(i) To study the growth and biomass accumulation pattern in leaf, stem, root and rhizomes during different growth stages in three ginger varieties, (ii) to study the influence of gas exchange parameters and endogenous hormonal (auxin and cytokinin) levels on the development of rhizomes and (iii) to study the rhizome bulking process both in terms of dry matter and starch accumulation in rhizomes.

\section{Materials and methods}

Ginger varieties viz., IISR Varada, IISR Rejatha and IISR Mahima were planted in ICARIISR Experimental Farm, Peruvannamuzhi in RBD with five replicates containing 40 plants in each replication. Six plants from each of these varieties were sampled (destructive sampling) at 30-day intervals starting from 60 days after planting (DAP) for dry matter and metabolite partitioning and hormonal studies. Observation on plant height, number of leaves, leaf area and number of tillers per plant were also recorded at an interval of 30 days starting from 60 DAP. Leaf area was determined as per Kandiannan et al. (2009). Indole3-acetic acid (IAA) and cytokinin were estimated using the ELISA kits (Sigma Aldrich) for IAA and zeatin riboside detection. One gram of leaf sample was cut into small pieces, ground in $5 \mathrm{~mL}$ of 50 per cent methanol under ice-cold condition, centrifuged at $10000 \mathrm{rpm}$ for 15 minutes; the supernatant was collected and was directly used for IAA and zeatin riboside quantification. Starch was estimated using the anthrone method and reducing sugars by the Nelson-Somogyi method (Sadasivam and Manickam, 2005). Photosynthetic rate, transpiration rate and leaf temperature were measured in situ at 3, 4 and 5 months after planting using CI-340 photosynthesis system (CID Inc, USA).
Statistical analysis was conducted using the mstatc package.

\section{Results and discussion}

\section{Morphological parameters in ginger varieties}

Morphological parameters such as plant height, number of tillers per plant, number of leaves and leaf area per plant were recorded in ginger varieties viz., IISR Varada, IISR Rejatha and IISR Mahima at $60,90,120$ and 150 days after planting. IISR Varada recorded the maximum number of tillers at all growth stages, IISR Mahima recorded maximum leaf area per plant, while IISR Rejatha recorded maximum plant height. IISR Rejatha recorded the least leaf area per plant (Table 1). Maximum tiller production and leaf area accumulation occurred between 60 and 120 days in all three varieties.

\section{Biomass partitioning to various organs during growth stages}

Partitioning studies in three different varieties of ginger (viz., IISR Varada, IISR Rejatha and IISR Mahima) showed that at 60 days after planting (DAP), shoots received 70.4 to 71.8 per cent biomass and rhizomes received 21.0 to 22.6 per cent while at 150 DAP, shoots received 22.4 to 29.0 per cent and rhizomes received 67.0 to 73.4 per cent of the total biomass (Table 2). Among the varieties, IISR Varada showed maximum partitioning of dry matter into rhizomes and minimum into the root and shoot compared to other varieties at all the observation days. Biomass partitioning data revealed that active biomass accumulation stage is between 60 and 150 DAP in all three varieties. Till 60 DAP, the shoot was the major sink which received about 70 to 72 per cent dry matter in different varieties. But at 90 DAP, dry matter partitioning to shoot and rhizome were almost equal;

Table 1. Morphological parameters in ginger varieties at different growth stages

\begin{tabular}{|c|c|c|c|c|c|c|c|c|c|c|c|c|c|c|c|c|}
\hline \multirow[t]{2}{*}{ Variety } & \multicolumn{4}{|c|}{ Plant height (cm) } & \multicolumn{4}{|c|}{ No. of tillers per plant } & \multicolumn{4}{|c|}{ No. of leaves per plant } & \multicolumn{4}{|c|}{ Leaf area per plant $\left(\mathrm{cm}^{2}\right)$} \\
\hline & $\begin{array}{c}60 \\
\text { DAP }\end{array}$ & $\begin{array}{c}90 \\
\text { DAP }\end{array}$ & $\begin{array}{c}120 \\
\text { DAP }\end{array}$ & & $\begin{array}{c}60 \\
\text { DAP }\end{array}$ & $\begin{array}{c}90 \\
\text { DAP }\end{array}$ & $\begin{array}{c}120 \\
\text { DAP }\end{array}$ & $\begin{array}{l}150 \\
\text { DAP }\end{array}$ & $\begin{array}{c}60 \\
\text { DAP }\end{array}$ & $\begin{array}{c}90 \\
\text { DAP }\end{array}$ & $\begin{array}{c}120 \\
\text { DAP }\end{array}$ & $\begin{array}{c}150 \\
\text { DAP }\end{array}$ & $\begin{array}{c}60 \\
\text { DAP }\end{array}$ & $\begin{array}{c}90 \\
\text { DAP }\end{array}$ & $\begin{array}{c}120 \\
\text { DAP }\end{array}$ & $\begin{array}{l}150 \\
\text { DAP }\end{array}$ \\
\hline ניחה & 24.7 & 32.5 & 38.3 & 45.5 & 1.6 & 4.5 & 6.1 & 7.7 & 14.3 & 78.3 & 94.2 & 107 & 273.5 & 1497.9 & 1802.0 & 20460 \\
\hline IISR Mahima & 23.2 & 31.7 & 36.8 & 43.8 & 14 & 5.0 & 6.5 & 8.1 & 14.5 & 76.2 & 91.0 & 102 & 328.9 & 1728.2 & 2063.9 & 2313.6 \\
\hline IISR Varada & 22.4 & 30.5 & 35.7 & 42.2 & 1.5 & 5.2 & 7.0 & 8.9 & 15.0 & 80.1 & 96.5 & 112 & 310.3 & 1653.9 & 1992.5 & 2311.5 \\
\hline $\mathrm{D}($ at $5 \%)$ & NS & NS & 2.4 & 2.6 & NS & NS & 0.5 & 0.6 & NS & 3.2 & 3.6 & 4.5 & 23.4 & 41.2 & 35.2 & 26.3 \\
\hline
\end{tabular}


Table 2. Dry matter partitioning in ginger varieties

\begin{tabular}{|c|c|c|c|c|}
\hline Days after planting & Total DW per plant (g) & Shoot (\%) & Rhizome (\%) & $\operatorname{Root}(\%)$ \\
\hline \multicolumn{5}{|l|}{ IISR Mahima } \\
\hline 60 & $4.3(6.9) *$ & 71.2 & $21.4(21.4) * *$ & 7.4 \\
\hline 90 & $23.6(37.9)$ & 48.2 & $46.1(24.7)$ & 4.7 \\
\hline 120 & $41.8(67.1)$ & 37.2 & $59.0(12.9)$ & 4.0 \\
\hline 150 & $56.1(90.0)$ & 29.0 & $67.0(8.0)$ & 4.0 \\
\hline 180 & $62.3(100)$ & 22.0 & $74.2(7.2)$ & 3.8 \\
\hline \multicolumn{5}{|l|}{ IISR Rejatha } \\
\hline 60 & $4.9(8.1)$ & 71.8 & $21.0(21.0)$ & 7.2 \\
\hline 90 & $22.5(37.2)$ & 47.3 & $48.3(27.3)$ & 4.3 \\
\hline 120 & $39.4(73.5)$ & 36.1 & $60.2(11.9)$ & 3.7 \\
\hline 150 & $53.2(90.5)$ & 27.3 & $68.9(8.7)$ & 3.8 \\
\hline 180 & $58.4(100)$ & 20.9 & $75.4(6.5)$ & 3.7 \\
\hline \multicolumn{5}{|l|}{ IISR Varada } \\
\hline 60 & $5.8(8.3)$ & 70.4 & $22.6(22.6)$ & 7.0 \\
\hline 90 & $28.7(42.7)$ & 44.2 & $50.8(28.2)$ & 5.0 \\
\hline 120 & $47.8(74.5)$ & 31.3 & $64.3(13.5)$ & 4.4 \\
\hline 150 & $63.3(93.9)$ & 22.4 & $73.4(9.1)$ & 3.3 \\
\hline 180 & $67.8(100)$ & 18.1 & $78.9(5.5)$ & 3.0 \\
\hline
\end{tabular}

*values in parentheses show \% dry matter, ** values in parentheses show the incremental \% dry matter accumulation between previous and present DAP

in fact, rhizomes received more than shoot in IISR Varada. Hence, it can be said that the transition stage of shoot from the sink to the source is at 90 DAP. Radioactive labeling studies by Zhao et al. (1987) showed assimilates were translocated mainly to shoots and leaves during the seedling stage. Rhizomes received more label proportionally as the plants aged compared to above-ground parts. The main shoots contributed most to rhizome formation. Secondary shoots were not so efficient, and the youngest shoots contributed little to assimilation or export of ${ }^{14} \mathrm{C}$ (Zhao et al., 1987; Xu et al., 2004). Up to the vigorous growth stage of rhizomes, carbon

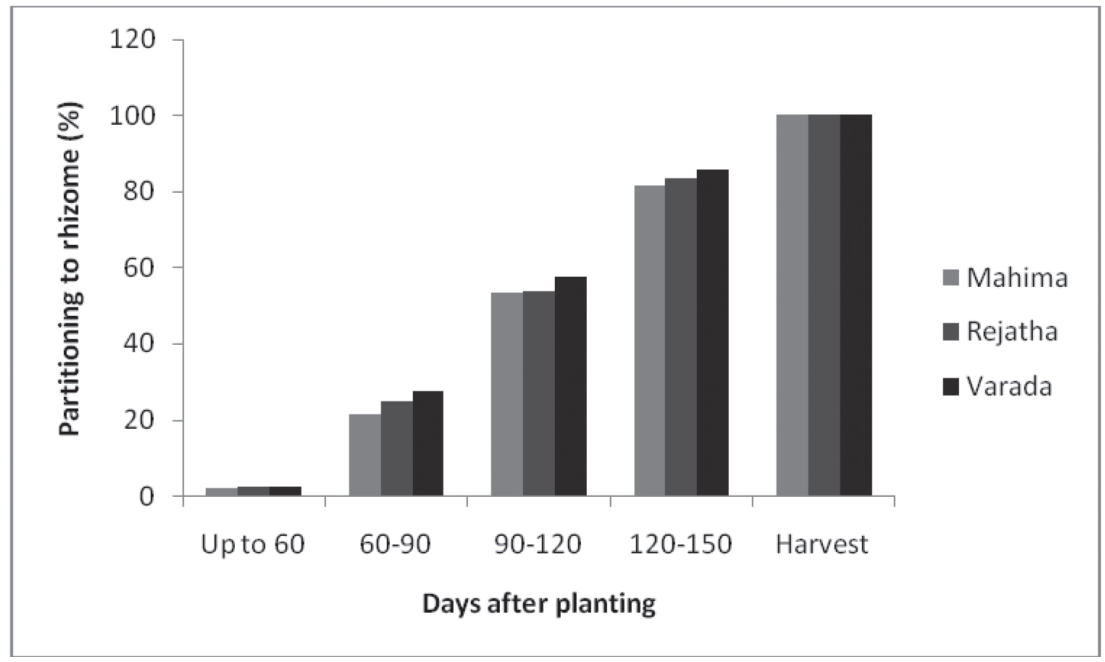

Fig. 1. Partitioning of dry matter to rhizomes at different crop growth stages 
Table 3. Plant hormones in ginger

\begin{tabular}{|c|c|c|c|c|c|c|c|c|}
\hline \multirow[t]{2}{*}{ Variety } & \multicolumn{4}{|c|}{ IAA (p moles) } & \multicolumn{4}{|c|}{ Zeatin riboside (p moles) } \\
\hline & 60 DAP & 90 DAP & 120 DAP & 150 DAP & 60 DAP & 90 DAP & 120 DAP & 150 DAP \\
\hline IISR Rejatha & 22.6 & 45.4 & 40.1 & 20.4 & 14.4 & 33.7 & 26.1 & 15.3 \\
\hline IISR Mahima & 19.4 & 46.5 & 38.1 & 21.7 & 12.2 & 28.5 & 24.7 & 13.4 \\
\hline IISR Varada & 21.5 & 52.0 & 43.8 & 22.4 & 14.8 & 35.2 & 30.3 & 14.2 \\
\hline $\mathrm{CD}$ at $5 \%$ & NS & 3.1 & 2.8 & 1.6 & NS & 2.1 & 3.4 & NS \\
\hline
\end{tabular}

assimilates mainly transported from the leaves to the rhizomes. Thus the rhizomes became the growth centres. In the present study also, after 150 DAP, the assimilate transport to the rhizome reduced, which could be because the active growth stage of the rhizome is over and that most of the assimilates from the shoot would have already been translocated to the rhizome, thus leading to reduced translocation rate.

The dry matter accumulation pattern in rhizomes revealed that maximum dry matter accumulation in rhizomes occurs between 60 and 150 DAP in all three varieties. The dry matter accumulation up to $60 \mathrm{DAP}$, and after $150 \mathrm{DAP}$ was very less (Fig. 1). As the entire shoot is dried up at harvest, partitioning to rhizomes is represented as 100 per cent (which is not true in the real sense). We can infer that the rapid rhizome development phase is between 60 and 150 days (the complete maturity of the crop occurred between 195 and 200 DAP).

\section{Starch and hormone accumulation}

Maximum starch accumulation in rhizomes occurred during 60-150 DAP in all three varieties. Starch accumulation increased from 6.4 to 40.4 per cent during this period in different varieties. In contrast, the starch content in the leaves was maintained at 6-7 per cent during the entire growth period (Fig. 2). IAA and zeatin riboside contents in rhizomes increased from 60 to 90 DAP, almost maintained up to 120 DAP and then declined. IISR Varada accumulated the highest starch, auxin and cytokinin at all growth stages. The decrease in IAA and zeatin riboside contents after 120 DAP maybe because these were utilized for rhizome growth, hence maximum dry matter accumulation in rhizome during this period. Earlier studies have shown that rhizome yield can be manipulated through growth regulators during the active growing period. Obasi and Atanu (2004) reported that rhizome yield significantly improved (36.4\% increase) by applying $250 \mathrm{ppm}$ CCC during the

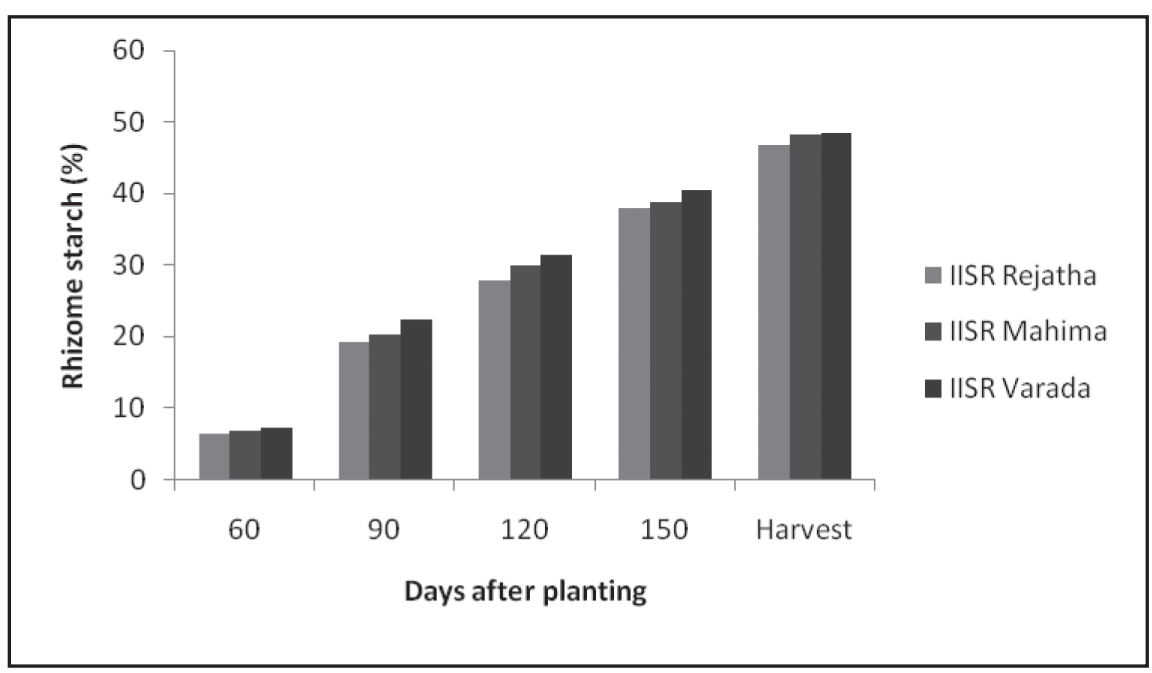

Fig. 2. Starch accumulation in rhizomes at different growth stages 
Table 4. Gas exchange parameters in ginger varieties

\begin{tabular}{|c|c|c|c|c|c|c|c|c|c|}
\hline \multirow[t]{2}{*}{ Variety } & \multicolumn{3}{|c|}{$\begin{array}{l}\text { Photosynthetic rate } \\
\left(\mu \text { moles } \mathrm{m}^{-2} \mathrm{~s}^{-1}\right) \\
\text { DAP }\end{array}$} & \multicolumn{3}{|c|}{$\begin{array}{c}\text { Transpiration rate } \\
\text { (m moles) } \\
\text { DAP } \\
\end{array}$} & \multicolumn{3}{|c|}{$\begin{array}{c}\text { Stomatal conductance } \\
(\mu \text { moles }) \\
\text { DAP } \\
\end{array}$} \\
\hline & 90 & 120 & 150 & 90 & 120 & 150 & 90 & 120 & 150 \\
\hline IISR Rejatha & 6.3 & 7.0 & 5.8 & 2.71 & 3.12 & 2.51 & 0.08 & 0.10 & 0.07 \\
\hline IISR Mahima & 6.5 & 7.4 & 6.0 & 2.78 & 3.18 & 2.56 & 0.08 & 0.11 & 0.07 \\
\hline IISR Varada & 7.1 & 8.2 & 7.0 & 2.97 & 3.34 & 2.89 & 0.09 & 0.11 & 0.09 \\
\hline $\mathrm{CD}(5 \%)$ & 0.4 & 0.6 & 0.5 & NS & NS & 0.21 & NS & NS & NS \\
\hline
\end{tabular}

active rhizome growth period. Starch and crude fibre contents showed a significant positive correlation with yield, while the crude fibre was negatively correlated (Shankar and Muthuswami, 1985). Phogat and Singh (1987) reported that $200 \mathrm{ppm}$ etherel enhanced rhizome yield.

The starch accumulation pattern in rhizomes is depicted in Figure 2. The starch accumulation increased with an increase in rhizome growth and reached maximum at harvest. Xu et al. (2008) also noted that starch and soluble sugar contents of fresh rhizomes increased with growth. Like dry matter accumulation, maximum starch accumulation occurred between 60 and 150 DAP. Per cent starch accumulation before 60 and after 150 DAP was very less. From both dry matter and starch accumulation pattern, it can be concluded that most rhizome bulking in ginger occurs between 60 and 150 DAP.

\section{Gas exchange parameters}

Photosynthetic rate $(\mathrm{Pn})$ varied from 5.8 to 8.2 in different ginger varieties from 90 to 150 DAP. Pn was maximum $\left(7.0-8.2 \mu \mathrm{mol} \mathrm{m}^{-2} \mathrm{~s}^{-1}\right)$ at 120 DAP. IISR Varada had the highest Pn (Table 4). For the same Pn, IISR Varada had lower transpiration and stomatal conductance compared to IISR Rejatha and IISR Mahima. Both transpiration rate and stomatal conductance were higher at 120 DAP than 90 DAP in all three varieties. Varada had a lower transpiration rate compared to other varieties. Pn increased from 90 to 120 DAP, and after that, it started declining. But the rate of decrease was very less. Thus, we can assume that the photosynthetic rate is maintained from 90 to $150 \mathrm{DAP}$, positively correlated with the dry matter and starch accumulation in rhizomes during that period.
This again highlights that the metabolic machinery is very active from 90 to 150 days after planting, leading to the rapid development of rhizomes. Earlier studies showed that light plays a major role in photosynthesis. Photosynthesis was saturated at a light intensity of $642-867 \mu \mathrm{mol} \mathrm{m} \mathrm{m}^{2} \mathrm{~s}^{-1}$, which depended on leaf temperature. The light compensation point was in the range of 25 - $69 \mu \mathrm{mol}$ $\mathrm{m}^{2} \mathrm{~s}^{-1}$, and it increased with increasing leaf temperature (Xi Zhen et al., 1998). LAI and DM yield was highest with 20 per cent shading ( 8.18 and $25.32 \mathrm{~g}$ plant $^{-1}$, respectively) and decreased with higher shade levels (Sreekala and Jayachandran, 2001). Wilting markedly decreased the rate of photosynthesis (Zhao et al., 1991). With increased light intensities from 15.61 to $104.81 \mathrm{klx}$, rhizome yield decreased from 13,487 to $2666 \mathrm{~kg} \mathrm{ha}^{-1}$ (Shankar and Muthuswamy, 1988).

\section{Conclusion}

Maximum tiller production and leaf area accumulation occurred between 60 and 120 days after planting (DAP) in all three varieties. Photosynthetic rate and hormone contents (auxin and cytokinin) increased from 90 to 120 DAP, peaked at 120 DAP and then started declining. Biomass partitioning data revealed that the active biomass accumulation stage is between 60 and 150 DAP. The dry matter accumulation pattern in rhizomes also revealed that maximum dry matter accumulation in rhizomes also occurred between 60 and 150 DAP in all three varieties. Maximum starch accumulation in the rhizomes also occurred during the same period. These results suggest that most of the rhizome bulking process occurs between 60 and 150 DAP in ginger. 


\section{References}

Iwama, K., 2008. Physiology of the potato: New insights into root system and repercussions for crop management. Potato Research 51: 333 (doi: https://doi.org/10.1007/ s11540-008-9120-3).

Kandiannan, K., Utpala, P., Krishnamurthy, K.S., Thankamani, C.K., Srinivasan, V., 2009. Modeling individual leaf area of ginger (Zingiber officinale Roscoe) using leaf length and width. Scientia Horticulturae 120 (4): 532-537.

Obasi, M.O. and Atanu, S.O., 2004. Effect of growth regulators on growth, flowering and rhizome yield of ginger (Zingiber officinale Rosc.). Nigerian Journal of Horticulture Science 9: 69-73.

P'erez-Pazos, J.V., Rosero, A., Martínez, R., Jos'e P'erez, Morelo, J., Araujo, H. and Burbano-Erazo, E. 2021. Influence of morpho-physiological traits on root yield in sweet potato (Ipomoea batatas Lam.) genotypes and its adaptation in a sub humid environment. Scientia Horticulturae 275(3): (doi: https:// doi.org/10.1016/ j.scienta.2020.109703).

Phogat, K.P.S. and Singh, O.P. 1987. Effect of cycocel and etherel on growth and yield of ginger. Progressive Horticulture 19(3-4): 223-226.

Sadasivam, S. and Manickam, A. (2005) Biochemical Methods. $2^{\text {nd }}$ Edition, New Age International, New Delhi.

Shankar, C.R. and Muthuswami, S. 1985. Influence of CCC on the quality of ginger (Zingiber officinale Roscoe.) rhizome. South Indian Horticulture 33(4): 271-275.

Shankar, C.R. and Muthuswamy, S. 1988. Influence of light and temperature on leaf area index, chlorophyll content and yield of ginger. Journal of Maharashtra Agricultural University 13(2): 216-217.

Sreekala, G.S. and Jayachandran, B.K. 2001. Photosynthetic rate and related parameters of ginger under different shade levels. Journal of Plantation Crops 29(3): 50- 52.
Suhaimi, Y.M., Mohamad, A.M. and Adzemi, M.A. 2016 Effects of seed rhizome size on growth and yield of ginger cultivated using fertigation system. Journal of Tropical Agriculture and Food Science 44(2): 211-218.

Tao, G-Q., Stuart Letham, D., Jean W.H.Y., Kerong Zhang, Peter C.L.J, Owen Schwartz, Chin Wong, S. and Farquhar, G.D. 2010. Promotion of shoot development and tuberisation in potato by expression of a chimaeric cytokinin synthesis gene at normal and elevated $\mathrm{CO}_{2}$ levels. Functional Plant Biology 37: 43-54.

Xi Zhen, A., Zhen Xian, Z., Zhi Feng, C. and LiPing, C., 1998. Changes in photosynthetic rate, MDA content and the activities of protective enzymes during development of ginger leaves. Acta Horticulturae Sinica 25(3): 294-296.

Xu, K., Guo, Y.Y. and Wang, X.F., 2004. Studies on the photosynthetic characteristics of ginger. In: The Future for Medicinal and Aromatic Plants. (Eds.) Craker Simon, L.E., Jatisatienr, J.E., Lewinsohn, A., Proceedings of the XXVI International Horticultural Congress Acta Horticulturae, Toronto, Canada, pp. 347-353.

Xu, K., Kang, L.M., Zhen, Y.Q. and Su, H., 2008. Changes of carbon and nitrogen nutrition during growth of ginger. In: Proceedings of the International Symposium on Plants as Food and Medicine: The Utilization and Development of Horticultural Plants for Human Health, (Eds.) Gardner, G., Craker, L.E., IHC 2006 Acta Horticulturae, Seoul, Korea, pp. 263-268.

Zhao, D.W., Liu, S.L. and Chen, L.P., 1987. A study on the characteristics of translocation and distribution of ${ }^{14} \mathrm{C}$ labelled assimilates in Lai-wu ginger. Acta Horticulturae Sinica 14(2): 119-124.

Zhao, D.W., Xu, K. and Chen, L.P., 1991. A study of the photosynthetic characteristics of ginger. Acta Horticulturae Sinica 18(1): 55-60. 